\section{Oral midazolam premedication for children with congenital cyanotic heart disease under- going cardiac surgery: a comparative study}

To determine whether oral midazolam is a safe and effective alternative to our current standard premedication for children with cyanotic congenital heart disease (CCHD), 30 children aged 1-6 yr, scheduled for elective cardiac surgery, were studied. The children were randomly assigned to one of two groups: Group I received oral midazolam $0.75 \mathrm{mg} \cdot \mathrm{kg}^{-1} 30 \mathrm{~min}$ before separation from their parents in the surgical waiting area, and Group II received oral or rectal pentobarbitone $2 \mathrm{mg} \cdot \mathrm{kg}^{-1}$ at $90 \mathrm{~min}$, and morphine $0.2 \mathrm{mg} \cdot \mathrm{kg}^{-1}$ and atropine 0.02 $\mathrm{mg} \cdot \mathrm{kg}^{-1}$ im at $60 \mathrm{~min}$ before separation. Heart rate, haemoglobin oxygen saturation $\left(\mathrm{SpO}_{2}\right)$ and anxiolysis and sedation scores were recorded at four times during the study: at baseline (immediately before premedication), immediately after administration of the premedication, at separation of children from parents in the waiting area and at the time of application of the face mask in the operating room. We found that in Group I, anxiolysis improved at separation from parents compared with baseline $(P<0.05)$ and sedation increased both at separation and on mask application $(P<0.05)$, whereas in Group II anxiolysis did not change at any time and sedation increased only at separation $(P<0.05)$. Intramuscular injection of morphine produced a transient decrease in mean $\mathrm{SpO}_{2}$ (from

\section{Key words}

ANAESTHESIA: paediatric;

PREMEDICATION: midazolam, oral;

SURGERY: cardiac.

From the Department of Anaesthesia and the Research Institute, The Hospital for Sick Children, Toronto, Ontario, Canada.

Address correspondence to: Dr. E.J. Hartley, Department of Anaesthesia, The Hospital for Sick Children, 555 University Avenue, Toronto, Ontario, Canada M5G 1 X8.

Accepted for publication 16th June, 1993.
$84 \%$ to $76 \%)(P<0.05)$ that did not occur after ingestion of oral midazolam. The results of this study indicate that oral midazolam is a safe and effective replacement for the standard premedication for children with $\mathrm{CCHD}$ undergoing cardiac surgery and avoids the decrease in $\mathrm{Sp} \mathrm{O}_{2}$ associated with im injections.

Dans le but de déterminer si le midazolam oral est une alternative aussi sûre et efficace que notre prémédication habituelle pour des enfants en attente de chirurgie pour des maladies cardiaque cyanogènes, nous avons étudié 30 enfants âgés de un à six ans programmés pour une chirurgie cardiaque non urgente. Les enfants sont distribués au hasard entre deux groupes: les enfants du groupe I reçoivent du midazolam oral $0,75 \mathrm{mg} \cdot \mathrm{kg}^{-1} 30 \mathrm{~min}$ avant dêtre séparés de leurs parents en salle d'attente chirurgicale, ceux du groupe II reçoivent du pentobarbitone oral ou rectal $2 \mathrm{mg} \cdot \mathrm{kg}^{-1}$ à $90 \mathrm{~min}$, de la morphine $0,2 \mathrm{mg} \cdot \mathrm{kg}^{-1}$ et de l'atropine $0,02 \mathrm{mg} \cdot \mathrm{kg}^{-1} \mathrm{im} 60 \mathrm{~min}$ avant la séparation parentale. La fréquence cardiaque, la saturation oxyhémoglobinée $\left(\mathrm{SpO}_{2}\right)$ et les scores de sédation et d'anxiolyse sont enregistrés à quatre reprises pendant la période d'étude: comme valeur de départ (immédiatement avant la prémédication), immédiatement après l'administration de celleci, à la séparation des enfants de leur parents dans la salle d'attente, et au moment de l'application du masque en salle d'opération. Nous avons constaté que dans le groupe I, l'anxiolyse s'améliore au moment de la séparation parentale comparativement à la ligne de base $(P<0,05)$ et que la sédation augmente aussi bien à la séparation qu'à l'application du masque $(P<0,05)$. Dans le group II, l'anxiolyse ne varie en aucun temps et la sédation n'augmente qu'à la séparation $(P<0,05)$. Linjection intramusculaire de morphine entraîne une baisse transitoire de la $\mathrm{SpO}_{2}$ (de 84\% à 76\%) $(P<0,05)$ qui ne survient pas après le midazolam oral. Cette étude montre que le midazolam oral peut remplacer efficacement et en toute sécurité la prémédication standard chez les porteurs de maladies 
cardiaques cyanogènes infantiles et éviter la chute de $\mathrm{SpO}_{2}$ associée à linjection im de morphine.

Premedication before surgery is recommended for children with cyanotic congenital heart disease (CCHD) in order to minimize the crying and struggling and the resultant decrease in haemoglobin oxygen saturation $\left(\mathrm{SpO}_{2}\right)$ that may occur at the time of separation from their parents and during induction of anaesthesia. ${ }^{1-3}$ The premedication regimen currently used in our institution includes oral or rectal pentobarbitone followed by an im injection of morphine and atropine. ${ }^{3,4}$ The distress caused by the im injection is sufficient to produce a transient decrease in $\mathrm{SpO}_{2}$ that does not occur after oral or rectal drug administration. ${ }^{5}$

Oral midazolam has been shown to be a safe and effective premedicant in healthy children (ASA I or II) undergoing ambulatory surgery. ${ }^{6,7}$ The purpose of this study was to determine whether oral midazolam is a safe and effective replacement for our present two-step premedication regimen for children with CCHD who are scheduled for cardiac surgery.

\footnotetext{
Methods

After institutional review board approval and written parental consent, 30 children (ages 1-6 yr) with CCHD scheduled for elective cardiac surgery were studied. Children with genetic or central nervous system abnormalities, allergy to one of the study drugs, or $<10 \mathrm{~kg}$ in weight were excluded. Age, weight, sex, haemoglobin concentration, and type of cardiac lesion were recorded. The children were randomly assigned to one of two groups: Group I received oral midazolam $\left(0.75 \mathrm{mg} \cdot \mathrm{kg}^{-1}\right)$ mixed in an equal volume of chocolate-cherry syrup $30 \mathrm{~min}$ preoperatively. Group II received oral or rectal pentobarbitone $\left(2 \mathrm{mg} \cdot \mathrm{kg}^{-1}\right) 90 \mathrm{~min}$ preoperatively and im morphine $\left(0.2 \mathrm{mg} \cdot \mathrm{kg}^{-1}\right)$ and atropine $\left(0.02 \mathrm{mg} \cdot \mathrm{kg}^{-1}\right)$ $60 \mathrm{~min}$ preoperatively. Children were separated from their parents by a nurse immediately before induction of anaesthesia.

Anxiolysis and sedation scores were monitored continuously from five minutes before administration of the premedication until application of the face mask on induction of anaesthesia. Anxiolysis and sedation scores were recorded by an unblinded observer at baseline and at the time of administration of the premedication. Scores were assessed separately for pentobarbitone and then for morphine administration in Group II. Scores measured at the time the children were separated from their parents and when the face mask was applied during induction of anaesthesia were assessed by another observer who was unaware of the premedication. A four-point scale
}

was used to assess anxiolysis ((1) tearful or combative; (2) anxious but easily reassured; (3) calm; (4) asleep) and sedation ((1) alert/active; (2) awake/calm; (3) drowsy; (4) asleep). Interobserver agreement for both the anxiety and sedation scoring systems has been established previously. ${ }^{6}$

Heart rate and $\mathrm{SpO}_{2}$ were also monitored continuously from five minutes before administration of the premedication until application of the face mask during induction of anaesthesia. Both measurements were recorded at four epochs: before and at the time of the administration of the premedication (baseline), at the time of separation from the parents, and at the time of application of the face mask for the induction of anaesthesia.

Parents were interviewed one day after surgery to assess their impressions of the effectiveness of the premedication.

The unpaired $t$ test for parametric data and the Wilcoxon Signed Rank sum test for non-parametric data (sedation and anxiolysis scores) were used for statistical analysis of the data. Mean changes in heart rate and $\mathrm{SpO}_{2}$ within each group during the study period were analyzed using repeated measures of analysis of variance and the Student-Newman-Keuls test. Differences in heart rate and $\mathrm{SpO}_{2}$ between the two groups were analysed at each epoch using the Student's unpaired $t$ test. Statistical significance was accepted as $P<0.05$.

Sample size was determined using power analysis assuming $\alpha_{2}=0.05, \beta=0.20$, an incidence of behavioural upset after im injection of morphine of $78 \%{ }^{5}$ and after oral administration of midazolam of $18 \% .^{6}$

\section{Results}

The demographic data and type of cardiac anomaly are shown in Table I. The most common preoperative diagnosis was tetralogy of Fallot. Baseline heart rates and $\mathrm{SpO}_{2}$ did not differ between groups (Figures 1 and 2). Most children (83\%) were alert and active when the anaesthetist arrived to begin the study (baseline) (Table II). Baseline anxiety and sedation scores did not differ significantly between the two groups (Table II).

Although $40 \%$ ( 6 of 15 ) of the children became tearful/ combative when given oral midazolam their behavioural scores at that point did not differ from the corresponding baseline values. However, the im injection of morphine resulted in an increase in anxiety (Table II). All but one of the children became tearful/combative. This was accompanied by a transient decrease in mean $\mathrm{SpO}_{2}$, that did not occur in either group when oral or rectal medication was administered (Figure 1). The $\mathrm{SpO}_{2}$ did not change at any other time during the study. None of the children became apnoeic during the study.

The mean heart rate increased after ingestion of oral midazolam compared with baseline measurements (from 
TABLE I Demographic data

\begin{tabular}{|c|c|c|c|c|c|c|}
\hline Patient group & $\begin{array}{l}\text { Number of } \\
\text { patients }\end{array}$ & $\begin{array}{l}\text { Age* } \\
\text { (mo) }\end{array}$ & $\begin{array}{l}\text { Weight* } \\
(\mathrm{kg})\end{array}$ & $\begin{array}{l}\text { Haemoglobin* } \\
\left(g \cdot d t^{-1}\right)\end{array}$ & $\begin{array}{l}\text { Male: } \\
\text { female }\end{array}$ & $\begin{array}{l}\text { Diagnosis } \\
(n)\end{array}$ \\
\hline $\begin{array}{l}\text { Group I: midazolam } \\
\text { Group II: standard }\end{array}$ & 15 & $29.9 \pm 12.6$ & $11.9 \pm 1.8$ & $150 \pm 18$ & $9: 6$ & $\operatorname{TOF}(7), \operatorname{TGV}(1), \operatorname{PA}(2), \operatorname{SV}(3), \mathrm{TA}(2)$ \\
\hline premedication $\dagger$ & 15 & $37.2 \pm 20.7$ & $12.9 \pm 2.6$ & $158 \pm 30$ & $12: 3$ & TOF (9), PA (3), TGV (1), DORV (1), SV (1) \\
\hline
\end{tabular}

TOF, tetralogy of Fallot; TGV, transposition of great vessels; PA, pulmonary atresia; SV, single ventricle; DORV, double outlet right ventricle; TA, tricuspid atresia.

*Data are means $\pm \mathrm{SD}$.

$\nmid$ Rectal or oral pentobarbitone $\left(2 \mathrm{mg} \cdot \mathrm{kg}^{-1}\right)$, im morphine $\left(0.2 \mathrm{mg} \cdot \mathrm{kg}^{-1}\right)$ and atropine $\left(0.02 \mathrm{mg} \cdot \mathrm{kg}^{-1}\right)$.

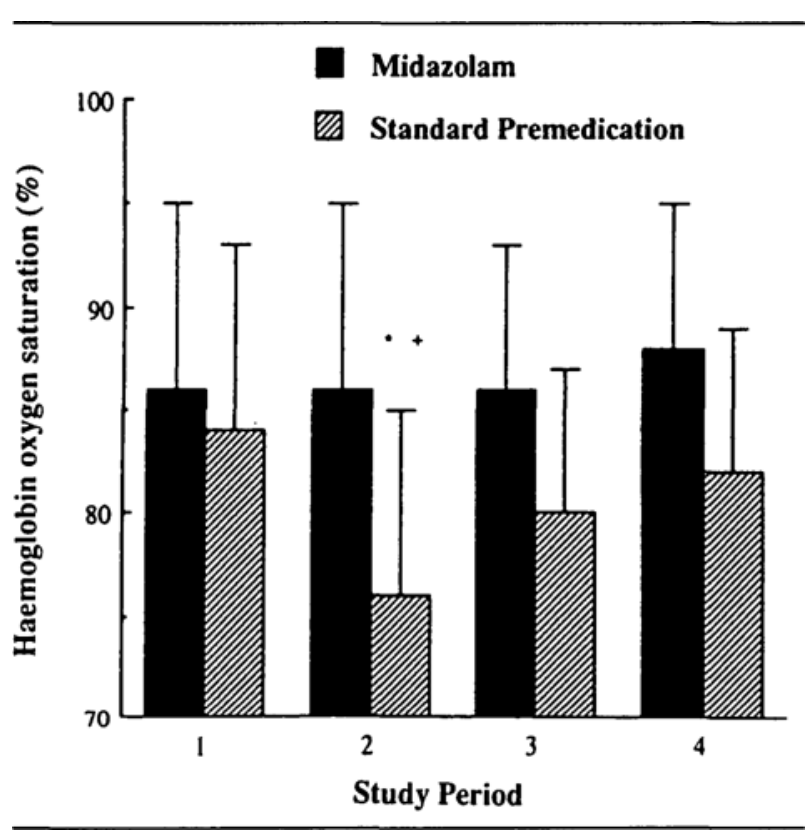

FIGURE 1 Percent haemoglobin oxygen saturation (mean \pm SD) in children with congenital cyanotic heart disease receiving either oral midazolam or the standard premedication. Study periods: 1, baseline; 2 , administration of midazolam or morphine; 3 , separation from parents; 4, mask application. *Statistically significant difference within a group compared with baseline of that group $(P<0.05)$. †Statistically significant difference between midazolam and standard premedication group $(P<0.05)$.

107 to 115 beats $\cdot \min ^{-1}$ ). This persisted during separation from parents and on application of the face mask. The mean heart rate also increased after intramuscular injection of morphine compared with baseline (from 104 to 129 beats $\cdot \min ^{-1}$ ). The increase in heart rate after intramuscular morphine exceeded that which occurred after both oral midazolam and pentobarbitone $(P<0.05$; Figure 2).

Midazolam produced anxiolysis and sedation when the children were separated from their parents compared with their baseline scores. Sedation scores in the midazolam group were also greater than baseline scores during mask

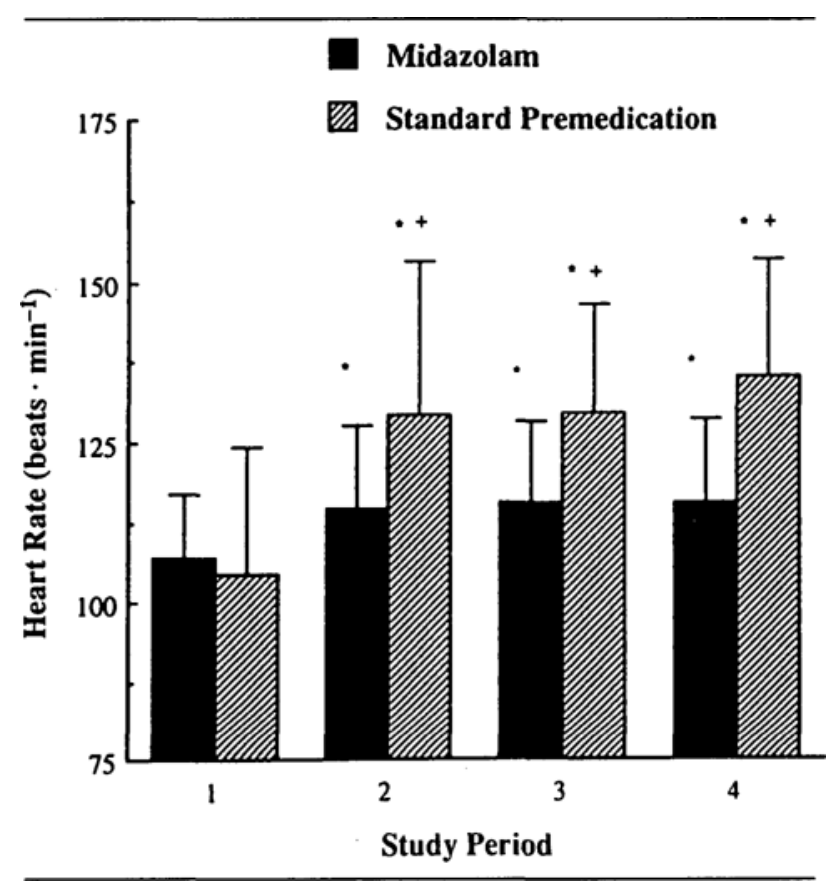

FIGURE 2 Heart rate (mean \pm SD). Study periods: 1, baseline; 2 , administration of midazolam or morphine; 3 , separation from parents; 4, mask application. *Statistcally significant differences within group compared to baseline $(P<0.05)$. †Statistically significant differenoes between midazolam and standard premedication group $(P<0.05)$.

placement $(P<0.05)$. In Group II, anxiolysis scores did not change at the time of separation or mask placement compared with baseline, whereas sedation increased when the children were separated from their parents but not when the mask was placed $(P<0.05)$. The mean $\mathrm{SpO}_{2}$ at the times of separation and mask placement was similar to baseline value for both groups (Figure 1).

Intramuscular morphine was associated with greater anxiety than oral ingestion of midazolam $(P<0.05$; Table II). At no other time were there between-group differences in anxiolysis or sedation scores.

The $\mathrm{SpO}_{2}$ levels decreased from a baseline value of $93 \%$ to $70 \%$, and the heart rate increased from baseline 
TABLE II Sedation and anxiolysis scores

\begin{tabular}{|c|c|c|c|c|c|c|c|c|}
\hline \multirow[b]{3}{*}{ Study periods for } & \multicolumn{8}{|c|}{ Percentage of patients } \\
\hline & \multicolumn{4}{|c|}{ Anxiolysis score ${ }^{a}$} & \multicolumn{4}{|c|}{ Sedation score ${ }^{b}$} \\
\hline & 1 & 2 & 3 & 4 & 1 & 2 & 3 & 4 \\
\hline \multicolumn{9}{|l|}{ Midazolam Group I } \\
\hline - Baseline & 27 & 60 & 13 & 0 & 80 & 20 & 0 & 0 \\
\hline - Oral midazolam & 40 & 47 & 13 & 0 & 87 & 13 & 0 & 0 \\
\hline - Separation ${ }^{c}$ & 27 & 0 & 73 & 0 & 27 & 40 & 33 & 0 \\
\hline - Mask applicationd & 27 & 20 & 53 & 0 & 27 & 53 & 20 & 0 \\
\hline \multicolumn{9}{|l|}{ Standard Group II } \\
\hline - Baseline & 46 & 27 & 27 & 0 & 87 & 13 & 0 & 0 \\
\hline - Pentobarbitone & 67 & 20 & 13 & 0 & 87 & 13 & 0 & 0 \\
\hline - Morphine/atropine $e^{c}$ & 93 & 7 & 0 & 0 & 93 & 7 & 0 & 0 \\
\hline - Separation ${ }^{d}$ & 20 & 27 & 40 & 13 & 20 & 40 & 27 & 13 \\
\hline - Mask application & 40 & 47 & 13 & 0 & 47 & 40 & 13 & 0 \\
\hline
\end{tabular}

"Anxiolysis score: 1, tearful/combative; 2 , anxious but easily reassured; 3 , calm; 4, asleep.

bedation score: 1 , alert/active; 2 , awake/calm; 3 , drowsy but responds readily to verbal commands/light touch; 4 , asleep.

${ }^{c} P<0.05$ anxiolysis and sedation scores compared with baseline.

${ }^{d} P<0.05$ sedation scores compared with baseline.

${ }^{e} P<0.05$ anxiolysis scores compared with baseline.

91 to 140 beats $\cdot \mathrm{min}^{-1}$ in one child who received the standard premedication 15 min after the im morphine. This child was sleeping during this episode, but the $\mathrm{SpO}_{2}$ did not increase, even when the child was aroused. Supplemental inspired oxygen increased the $\mathrm{SpO}_{2}$ but not sufficiently to return to baseline levels.

Although more parents expressed satisfaction with the sedation achieved at the time of separation after premedication with midazolam than with the standard premedication (93\% vs $60 \%)$, this difference did not achieve statistical significance.

\section{Discussion}

The ideal premedication for children with CCHD should produce adequate sedation quickly, be available in a formulation which is acceptable to children, and maintain the $\mathrm{SpO}_{2}$. In a previous study, we demonstrated that an im injection causes an immediate, but transient, decrease in $\mathrm{SpO}_{2}$ in children with $\mathrm{CCHD}{ }^{5}$ In the present study, we demonstrated that oral midazolam was as effective as oral or rectal pentobarbitone followed by im morphine as a premedication for children with $\mathrm{CCHD}$ without the decrease in $\mathrm{SpO}_{2}$ that accompanies morphine injection. Although some children objected to the ingestion of the midazolam, this was not associated with a decrease in mean $\mathrm{SpO}_{2}$. In contrast, the intramuscular injection of morphine caused crying and distress of sufficient magnitude to produce a decrease in mean $\mathrm{SpO}_{2}$ in this cohort of children.

We compared oral midazolam with our standard premedication for children scheduled for open heart surgery and did not include a placebo group because the standard of practice for children with CCHD who present for elective cardiac surgery includes adequate premedication. ${ }^{3,4}$

One episode of haemoglobin oxygen desaturation (from $93 \%$ to $70 \%$ ) associated with an increase in heart rate occurred $15 \mathrm{~min}$ after morphine and atropine injection in a child with tetralogy of Fallot. At the time of desaturation the child was sleeping but easily arousable. Interestingly, the $\mathrm{SpO}_{2}$ did not increase even when the child was aroused. However, when oxygen was administered via face mask, the $\mathrm{SpO}_{2}$ did increase towards, but did not reach baseline levels. Although the child did receive his morning dose of propranolol, the desaturation may have resulted from sinus tachycardia induced by atropine which increased the magnitude of the right to left shunt.

Oral midazolam does not appear to compromise either ventilation or cardiovascular homeostasis and is unlikely to lead to sudden cardiorespiratory collapse. However, such an episode is possible particularly if the midazolam is retained in the mouth rather than swallowed, if it is administered to a child receiving erythromycin ${ }^{9}$ or in patients who are known to be sensitive to sedatives. With the exception of these circumstances, oral midazolam appears to be a safe and effective premedication in children with CCHD.

In conclusion, we have demonstrated that oral midazolam is as safe and effective as the standard premedication for preoperative preparation of children with CCHD undergoing cardiac surgery. Moreover, administration of oral midazolam obviates the need for intramuscular in- 
jections. The rapid onset of action of oral midazolam allows for administration of the midazolam $30 \mathrm{~min}$ before separation of the children from their parents.

\section{Acknowledgment}

This paper was prepared with the assistance of Medical Publications, The Hospital for Sick Children, Toronto, Ontario, Canada.

\section{References}

1 Moffitt EA, McGoon DC, Ritter DG. The diagnosis and correction of congenital cardiac defects. Anesthesiology 1970; 33: 144-60.

2 Seelye ER. Anaesthesia for children with congenital heart disease. Anaesth Intensive Care 1973; 1: 512-6.

3 Koch $F$. Perioperative management of children with congenital heart disease. In: Lake CL (Ed.). Pediatric Cardiac Anesthesia. Norwalk: Appleton \& Lange, 1988; 71-86.

4 Steward DJ. Manual of Pediatric Anesthesia, 3rd ed. New York: Churchill Livingstone, 1990; 264-5.

5 Stow PJ, Burrows FA, Lerman J, Roy WL. Arterial oxygen saturation following premedication in children with cyanotic congenital heart disease. Can J Anaesth 1988; 35: 63-6.

6 McMillan CO, Spahr-Schopfer IA, Sikich N, Hartley E, Lerman J. Premedication of children with oral midazolam. Can J Anaesth 1992; 39: 545-50.

7 Feld LH, Negus JB, White PF. Oral midazolam preanesthetic medication in pediatric outpatients. Anesthesiology 1990; 73: 831-4.

8 Krane EJ, Davis PJ, Smith RM. Preoperative preparation. In: Motoyama EK (Ed.). Smith's Anesthesia for Infants and Children. St. Louis: CV Mosby Company, 1990; 201-16.

9 Hiller A, Olkkola KT, Isohanni P, Saarnivaara $L$. Unconsciousness associated with midazolam and erythromycin. Br J Anaesth 1990; 65: 826-8. 